\title{
Femtosecond-assisted intracorneal ring segment complications in keratoconus: from novelty to expertise
}

This article was published in the following Dove Press journal:

Clinical Ophthalmology

\section{Amr Mounir \\ Gamal Radwan \\ Mahmoud Mohamed Farouk \\ Engy Mohamed Mostafa}

Department of Ophthalmology, Faculty of Medicine, Sohag University, Sohag, Egypt
Correspondence: Amr Mounir Department of Ophthalmology, Sohag University, Nasr City, Sohag 82524, Egypt Tel +20 I00 5026170

Emaildramrmonir@yahoo.com
Objectives: To document the difference between complication rate in the early curve of practicing intracorneal stromal rings and after gaining experience.

Patients and methods: A retrospective study of 623 eyes of 417 patients with keratoconus who underwent Keraring implantation using femtosecond laser for channel creation.

Results: The main outcome measures were reported intraoperative and postoperative complications. The overall complication rate was $12.7 \%$ ( 79 eyes) over the 4 years with 34 eyes in the first year $(5.5 \%)$ and six eyes in the fourth year $(0.96 \%)$. Over the 4 years of our practice, intraoperative complications were $7.1 \%$ and postoperative complications were $5.6 \%$. Yet, there was a significant difference in intraoperative complications between the first and the fourth year where it was $3.5 \%$ and $0.48 \%$, respectively. This also applies to the postoperative complication rate, which decreased from $1.9 \%$ to $0.5 \%$ in the fourth year.

Conclusion: Complications with femtosecond-assisted intracorneal stromal ring procedure can be reduced by experience, making this procedure a safe and effective means of treating keratoconus. Yet, there are some complications that cannot be avoided such as sterile keratitis.

Keywords: femtosecond laser, intracorneal rings, Kerarings, keratoconus

\section{Introduction}

Keratoconus is a progressive ectatic corneal disorder resulting in impairment of visual acuity as a result of progressive myopia, irregular astigmatism, and higher-order aberrations. ${ }^{1}$

A vast majority of options for the management of keratoconus have been described; these include rigid gas-permeable contact lenses, ${ }^{2}$ corneal collagen crosslinking, ${ }^{3}$ intrastromal corneal ring segment (ICRS) implantation, ${ }^{4,5}$ and lamellar or penetrating keratoplasty. ${ }^{6,7}$

The concept of ICRS was introduced in 1978, and it was first implanted in 1991 to correct myopia. ${ }^{8,9}$ In June 2004, the US Food and Drug Administration (FDA) approved the use of a special type of ICRS, Intacs (Addition Technology, Inc., Fremont, CA, USA), for the management of keratoconus. Now, ICRS is mostly used in patients with keratoconus and corneal ectasia. ${ }^{10,11}$ The original device was a nearly continuous ring of polymethyl methacrylate and evolved into segments. ${ }^{9}$ Different types of incomplete rings are available in the market: Intacs (AdditionTechnology, Inc.), Ferrara ring (Mediphacos, Inc., Belo Horizonte, Brazil), and Keraring (Mediphacos Ltd., Belo Horizonte, Brazil). ${ }^{12}$

ICRSs act by an "arc-shortening effect" on the corneal lamellae and flatten the central cornea by creating a second limbus of smaller diameter in the middle of 
the cornea. ${ }^{13}$ The main advantages of ICRS are safety, reversibility, stability, and individualized treatment of keratoconus depending on ring thickness, diameter, and centration. ${ }^{14-16}$ Channel creation for intracorneal rings can be done either by manual dissection or using femtosecond (FS) laser, which became widely accepted after the approval of its use by the FDA in the USA. ${ }^{17}$ FS laser is believed to reduce complications because of the rapidity, precision, ease of channel creation, and centration with minimal associated stromal edema. ${ }^{18,19}$ The aim of our study is to report complications of FS-assisted intrastromal corneal ring segment (FS-ICRS) procedure in a large case series and its rate over 4 years of our experience with special emphasis on the difference between the rate of complications between the first and the fourth year of our learning curve.

\section{Patients and methods}

This retrospective study was conducted at Sohag refractive center, Sohag, Egypt from January 2012 to January 2016. The study included 623 eyes of 417 patients of keratoconus grade 2 and grade 3 (according to Krumeich Amsler classification) with clear central cornea and age between 18 and 40 years. Corneal thickness was at least $350 \mu \mathrm{m}$ at the thinnest corneal point and at least $400 \mu \mathrm{m}$ at the incision site. Kerarings (Mediphacos, Belo Horizonte, Brazil) are segments with triangular cross-section, which induces a prismatic effect on the cornea. Kerarings are not FDA approved yet. Their apical diameter is $5 \mathrm{~mm}$ and the flat basis width is $0.6 \mathrm{~mm}$ with variable thickness $(0.15-0.30 \mathrm{~mm}$ thickness with $0.05 \mathrm{~mm}$ steps) and arc lengths $\left(90^{\circ}, 160^{\circ}\right.$ and $\left.210^{\circ}\right)$. The optical zone provided by Keraring segments is $5.0 \mathrm{~mm}$ in diameter. Eyes with previous post-refractive surgery ectasia, previous hydrops, scarring, and grade IV keratoconus were excluded from the study. In all cases, ICRS implantation was indicated because of a confirmed keratoconus diagnosis, poor patient motivation to wear contact lenses, or contact lens intolerance. All patients were evaluated for the following: uncorrected visual acuity (UCVA), best spectacle-corrected visual acuity (BSCVA), slit-lamp biomicroscopy, manifest and cycloplegic refraction, and corneal topography using Sirius Scheimpflug placido topography (Costruzione Strumenti Oftalmici, Florence, Italy). Pachymetry around the thinnest location was evaluated using the Sirius; the minimum thickness for implantation was $400 \mu \mathrm{m}$ at the incision site.

\section{Surgical technique}

The surgical procedures were performed by the four surgeons involved in this study under topical anesthesia and complete aseptic measures. The procedure was initiated by marking a reference point for centration (purkinje reflex). Intraoperatively, corneal thickness around the $5 \mathrm{~mm}$ circle was measured using ultrasonic pachymetry (Sonogage, Cleveland, $\mathrm{OH}, \mathrm{USA}$ ). The suction ring was applied. Next, the disposable glass lens of the laser system was applied to applanate the cornea. The $60 \mathrm{kHz}$ Intralase FS system (Advanced Medical Optics, Santa Ana, CA, USA) was used. Continuous circular stromal tunnel was created as recommended by the ring manufacturer and previous studies, ${ }^{20,21}$ at $80 \%$ depth of the thinnest location with inner diameter $5.00 \mathrm{~mm}$, outer diameter $5.90 \mathrm{~mm}$, entry cut length $1.40 \mathrm{~mm}$, and entry cut thickness $1 \mathrm{~mm}$ with ring energy $1.9 \mathrm{~mJ}$. Incision was created at the steepest axis. The choice of the number, arc, and the thickness of the ring was performed following the nomogram provided by the manufacturer. The ring segment was introduced by the Keraring forceps after dilating the tunnel by a blunt dilator. Finally, soft bandage contact lens was applied. Postoperatively, topical moxifloxacin and prednisolone acetate eyedrops were used every 2 hours for 2 days then every 6 hours for 2 weeks and then stopped. Topical preservative-free lubricants were also prescribed every 6 hours for 1 month. Contact lens was removed after 1 week. This study followed the tenets of Declaration of Helsinki and Ethical Board Committee approval from the Sohag Faculty of Medicine institution was obtained. No patient consent was required by the committee as it was a retrospective study, granted patient data confidentiality was taken into consideration.

\section{Follow-up evaluation}

The analysis comprised data from preoperative and 1, 6, and 12 months. The rate and types of complications were reported and analyzed all over the 4 years with emphasis on the differences between the first and the fourth year. Slit-lamp examination to evaluate ICRS position and corneal integrity was performed. Subsequent postoperative examinations included UCVA and best-corrected visual acuity, manifest refraction, slit-lamp evaluation, and corneal topography.

Statistical analysis was performed using SPSS for Windows software (version 15.0.1, SPSS, Inc.). The Student's $t$-test for paired data was used to compare the preoperative and postoperative data (keratometry, sphere, etc). Wilcoxon rank test was used for comparing the rate of complications between the first and the fourth year. To compare the rate of complications between surgeons, analysis of variance test was used. $p<0.05$ was considered statistically significant. 


\section{Results}

This study comprised 623 consecutive keratoconic eyes of 417 patients. The mean age of the 206 men and 211 women was $22.27 \pm 4.54$ years (range 18-37 years). All eyes completed the 1-year follow-up evaluation. The number of eyes that underwent ring implantation in the first year through the fourth year was $122,130,177$, and 194, respectively.

\section{Refractive outcomes}

The mean UCVA measured in logMAR was statistically significantly better postoperatively than preoperatively ( $p=0.002$; Table 1). The improvement in the UCVA remained unchanged at 6 and 12 months after surgery $(p=0.139)$. The average improvement of UCVA after 18 months compared to the preoperative state was 2 lines and statistically significant ( $p=0.002$ ). The average improvement of BSCVA was 0.7 lines during this period of time and not statistically significant $(p=0.19)$. There was a statistically significant reduction in spherical equivalent from preoperatively to 12 months postoperatively ( $p=0.003$ ). There was a statistically significant reduction in mean keratometry from preoperatively to 12 months postoperatively $(p<0.001)$ with a mean reduction of $2.96 \mathrm{D}$.

\section{Complications}

The overall complication rate was $12.7 \%$ (79 eyes) over the 4 years with 34 eyes in the first year $(5.5 \%)$ and six eyes in the fourth year $(0.96 \%)$ (Table 2$)$. There was no significant difference between occurrences of complications between the three surgeons $(p=0.2)$.

\section{Intraoperative complications}

Intraoperative complications occurred in 44 eyes (7.1\%), which are reported in Table 2. Most of the intraoperative

Table I Shows the main refractive outcomes over 18 months of follow-up

\begin{tabular}{llll}
\hline & Preoperative & $\begin{array}{l}\text { Postoperative } \\
\text { (I8 months) }\end{array}$ & p-value \\
\hline UCVA & $1.31 \pm 0.24$ & $1.1 \pm 0.21$ & 0.002 \\
BCVA & $0.79 \pm 0.24$ & $0.72 \pm 0.02$ & 0.19 \\
Sphere & $-7.6 \pm 5.29$ & $-5.16 \pm 4.01$ & 0.0003 \\
Cylinder & $-6.53 \pm 3.25$ & $-4.73 \pm 1.74$ & 0.03 \\
SER & $-10.86 \pm 5.7 \mathrm{I}$ & $-7.52 \pm 3.97$ & 0.0001 \\
KI & $49.13 \pm 3.13$ & $46.88 \pm 2.69$ & $<0.000$ I \\
K2 & $53.50 \pm 4.46$ & $49.83 \pm 3.18$ & $<0.000$ I \\
Mean keratometry & $51.31 \pm 3.68$ & $48.35 \pm 2.84$ & $<0.000$ I \\
Mean thinnest location & $428.5 \pm 26.25$ & $421.85 \pm 30.09$ & 0.13 \\
\hline
\end{tabular}

Abbreviations: BCVA, best-corrected visual acuity; SER, spherical equivalent refractive error; UCVA, uncorrected visual acuity. complications occurred in the beginning of the learning curve, $22(3.5 \%)$ eyes in the first year with only three complications $(0.48 \%)$ in the fourth year $(p=0.003)$. Vacuum loss occurred in eight eyes (1.3\%) before laser firing. Vacuum loss occurred mostly because of poor application of the cone or forcible squeezing of the patient. Reapplying the applanation cone and completing the procedure were done in all eyes. Incomplete tunnel creation occurred in six cases $(0.96 \%)$ and was mainly due to low setting of the power of the laser used or incomplete docking. Misdirection of the ring segment into either more superficial or deeper corneal layers occurred in six eyes that had incomplete tunnel creation and ended in one case by perforation into the anterior chamber (occurred in eye number 5 operated). The procedure was aborted and contact lens was applied and follow-up revealed no infection. This is explained by forcible pushing of the ring segment, which was avoided later on by caution and aborting implantation if met by resistance. Decentration of ring segments away from the reference point crossing the pupil (Figure 1) occurred in seven eyes. Patients were not looking directly into the light giving false center. As for implantation of inverted ring segment, it occurred in seven cases. The correct orientation of the ring segment with its apex upwards is essential for optimal results. This should be checked before implantation. Broken ring segments occurred in six cases: in two cases the rings were reported broken inside their packaging. In the other two cases, the segments were broken because of rough manipulation by the ring forceps. The last two were broken because of using a forceps that was not meant for Kerarings. As for the ring orifice, it was reported in three eyes that the end orifice was fractured because of clinging of the toothed ring forceps on the orifice. At those instances the ring was replaced for fear of either extrusion or imbedding into the walls of the tunnel causing decrease of the effect of the ring.

\section{Postoperative complications}

Rate of complication over the 4 years of our experience is 35 eyes $(5.6 \%)$. The rate in the first year was 12 eyes $(1.9 \%)$ and in the fourth year were three eyes $(0.5 \%)(p=0.05)$. Segment migration occurred in 10 eyes. Repositioning the segment inside the channel was the first step in management, while four eyes needed stitching at the incision. Two cases ended in extrusion. Incision opacification was noticed in six eyes, which did not progress nor affect visual acuity. Steroid-induced glaucoma was reported in four cases where they continued steroid for over 6 weeks. Intraocular pressure was controlled after discontinuation of steroids. Infectious keratitis occurred in four eyes $(0.64 \%)$. Onset of symptoms 
Table 2 Intraoperative and postoperative complications of femtosecond-assisted intracorneal stromal ring

\begin{tabular}{|c|c|c|c|c|c|}
\hline & $\begin{array}{l}\text { Overall rate of } \\
\text { complication } \\
\text { (623 eyes) }\end{array}$ & $\begin{array}{l}\text { First-year rate } \\
\text { of complication } \\
\text { ( } 122 \text { eyes) }\end{array}$ & $\begin{array}{l}\text { Second-year rate } \\
\text { of complication } \\
\text { ( } 130 \text { eyes) }\end{array}$ & $\begin{array}{l}\text { Third-year rate } \\
\text { of complication } \\
\text { ( } 177 \text { eyes) }\end{array}$ & $\begin{array}{l}\text { Fourth-year rate } \\
\text { of complication } \\
\text { (194 eyes) }\end{array}$ \\
\hline \multicolumn{6}{|l|}{ Intraoperative complications } \\
\hline Vacuum loss & 8 & 5 & I & 2 & I \\
\hline Incomplete tunnel creation & 6 & 3 & 2 & I & 0 \\
\hline Decentered created tunnel & 7 & 4 & I & I & I \\
\hline $\begin{array}{l}\text { Misdirection of ring } \\
\text { segment into stroma }\end{array}$ & 6 & 3 & 2 & I & 0 \\
\hline $\begin{array}{l}\text { Perforation into anterior } \\
\text { chamber }\end{array}$ & I & I & 0 & 0 & 0 \\
\hline Inverted implanted rings & 7 & 3 & 2 & I & I \\
\hline Broken body of Keraring & 6 & 3 & I & I & 0 \\
\hline Broken end orifice of ring & 3 & I & I & I & 0 \\
\hline \multicolumn{6}{|l|}{ Postoperative complications } \\
\hline Segment migration & 10 & 5 & 2 & 2 & I \\
\hline Segment extrusion & 4 & 1 & 2 & I & 0 \\
\hline Incision opacification & 4 & 1 & 2 & I & I \\
\hline Infective keratitis & 4 & 2 & I & I & 0 \\
\hline Corneal melting & I & I & 0 & 0 & 0 \\
\hline Sterile keratitis & 5 & I & I & 2 & I \\
\hline Steroid-induced glaucoma & 4 & I & 2 & 1 & 0 \\
\hline
\end{tabular}

varied from $<1$ week to 2 months postoperatively, depending on the infecting organism. Two eyes encountered infection after trivial trauma to the eye and the other two eyes had no predisposing factor. Culture from the conjunctival sac and cornea was positive in two cases with Staphylococcus aureus, while the other two came with pseudomonas sp. They were treated by topical and subconjunctival antibiotics with irrigation of the channel by antibiotics. Two eyes responded to treatment, while in the other two eyes, ring explantation was the management of choice (Figure 2). One eye proceeded to corneal melting despite ring removal. Healing in all cases ended by opacification along the tunnel (Figure 2C). Crystalline sterile keratitis (Figure 3 ) along the inner side of the created tunnel was noticed in three eyes $(0.48 \%)$.

\section{Discussion}

The use of the FS laser in corneal tunnel creation made the corneal ring implantation procedure faster, easier, safer with precise depth of implantation. ${ }^{5,22,23}$ In our study we do not aim to analyze the functional outcomes of the ICRS, yet we are more concerned about shedding light on the complications' rate and role of experience in decreasing preventable complications. The authors gained skill in surgical manipulation and postoperative care over the years of practice. This proved to play a role in reducing the rate of complications between the first and the fourth year, which was stressed in our study. Experience and growing confidence in management was a variable that was not addressed in previous studies.
The rate of complications varied vastly between studies because of variation in number of enrolled eyes and the difference in the type of ring segments used. Ratkay-Traub et al and Carrasquillo et $\mathrm{al}^{24,25}$ who used FS laser for channel creation reported no intraoperative complications while our study reported $7.1 \%$. Coskunseven et al reported $4 \%$ (33 eyes) intraoperative complications, which was also on a large case series (850 eyes) using FS inserted Kerarings. Yet, none of the above-mentioned studies reported any broken rings or inverted ring segments. In our study incomplete tunnel formation can be attributed to incomplete distribution of femto-laser treatment, so the tunnel was not created at one side or partially formed, which can be explained by inadequate docking and slight movement of patient head. This resulted in implantation of one segment, which affected the final refractive improvement required. Forcing of the ring segment should be avoided and aborting the procedure and rescheduling the patient for another trial would be a better option. On forcing the segment, it can be broken, which occurred in our series in two cases. Our study reported a high rate of ring migration (1.6\%). Ring migration is an early stage before extrusion, which might be due to thick segment in thin cornea, implantation of segments near incision site, or corneal melting. Whenever the segment approaches the incision site it should be closely observed and intervention is required if it is near the incision site by $0.5 \mathrm{~mm}$. Segment migration was less over the years as the surgeons tended to push the segment more into the tunnel by $1-2 \mathrm{~mm}$ to leave space for safe movement. It can solve the situation 
A

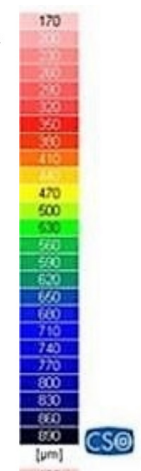

$n$
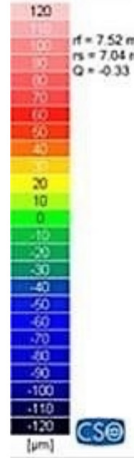

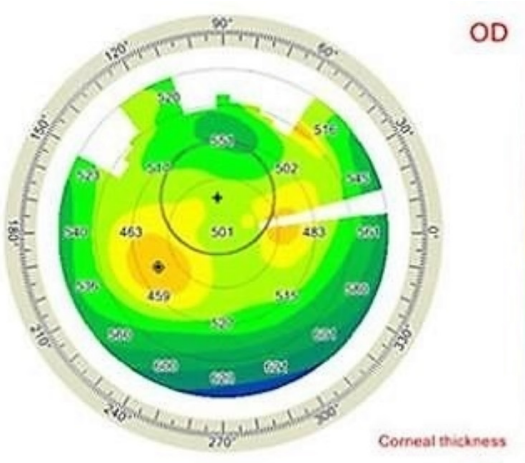

D

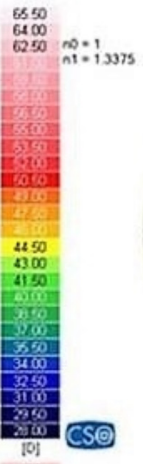

$O D$
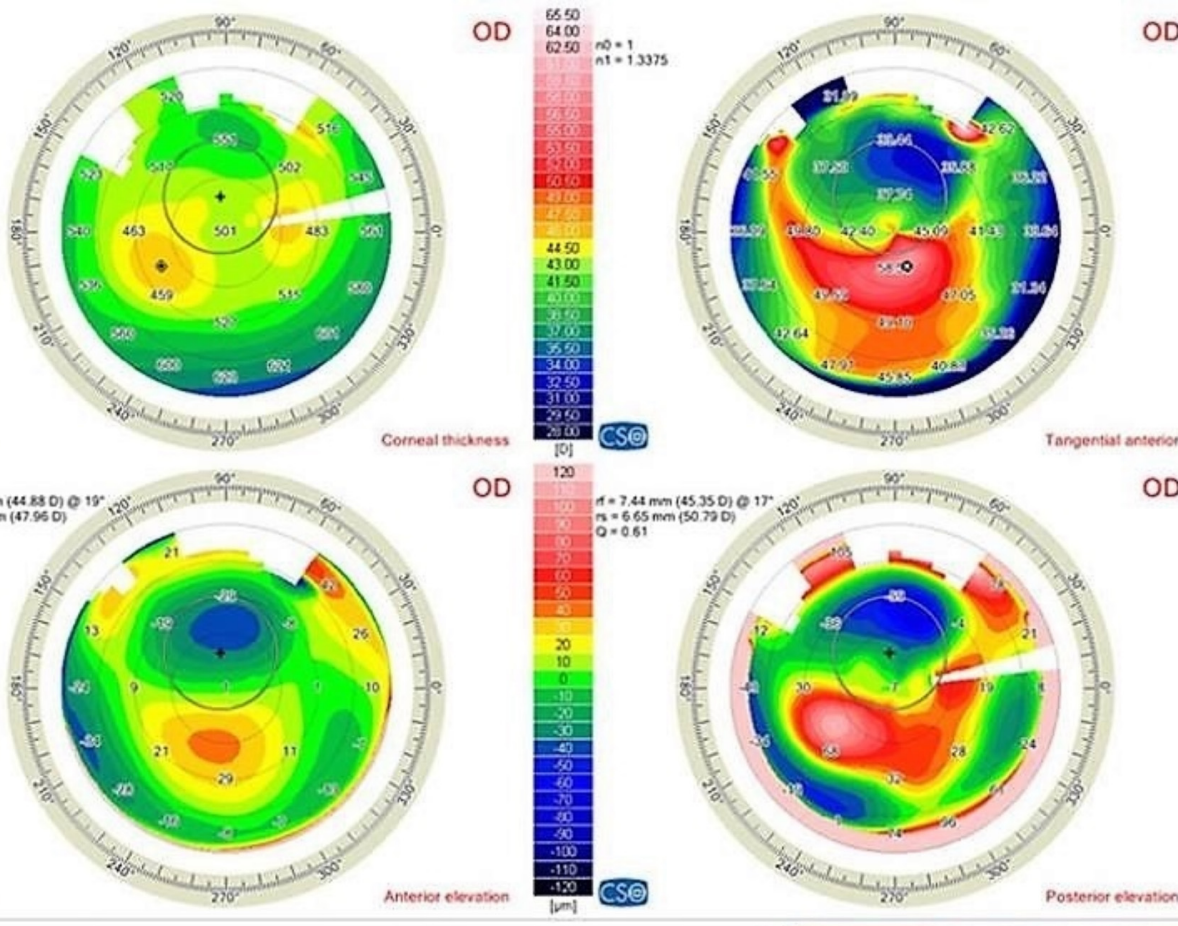

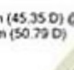
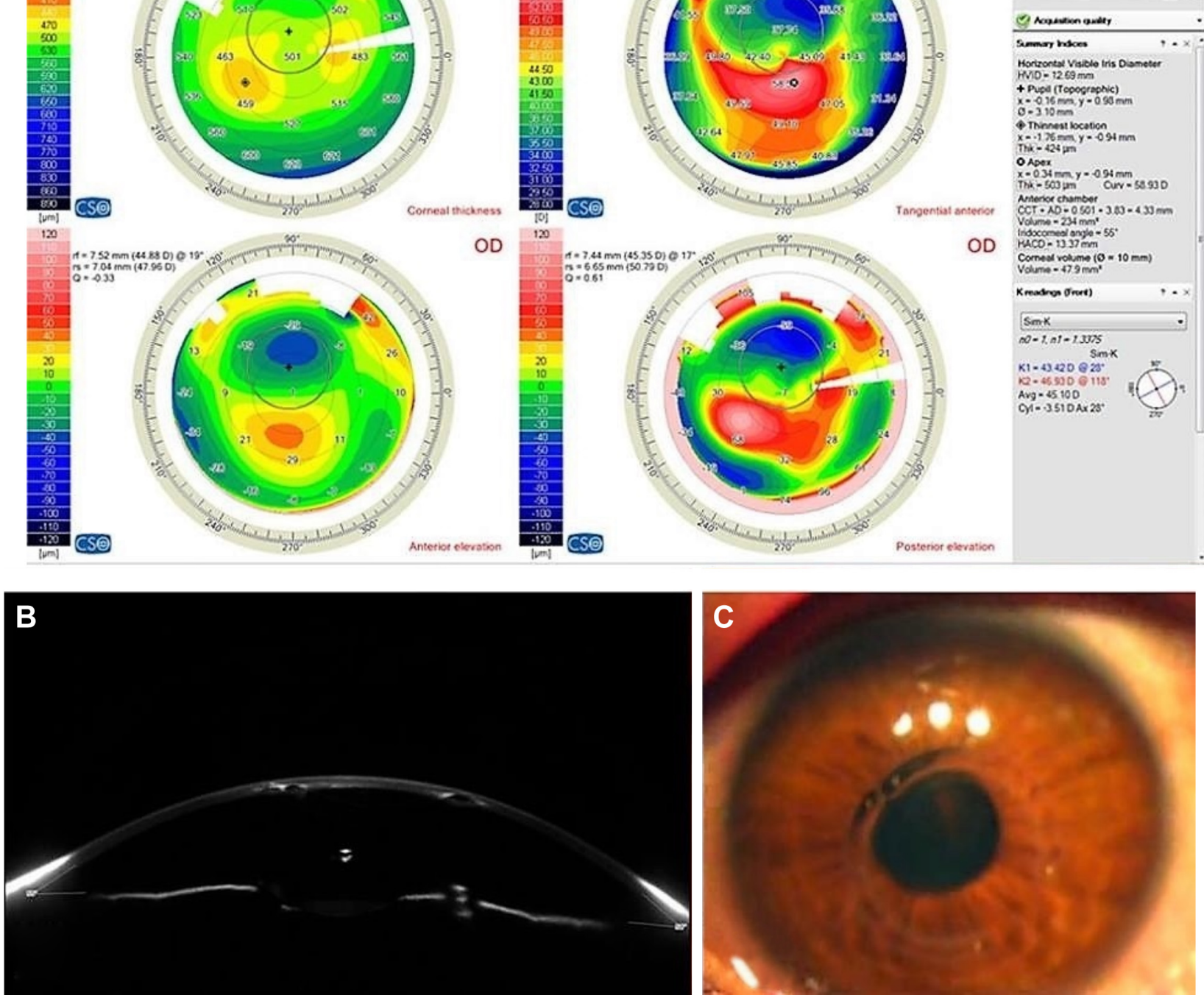

Figure I (A) Scheimpflug tomography by Sirius CSO showing decentered ring. (B) Scheimpflug image of the cornea showing decentered rings near toward the pupil. (C) Cornea view of the eye showing the Keraring crossing the pupil.

while in other instances; stitches are warranted until healing takes in. Incorrect misdirection of the ring segment in either superficial or deeper planes occurred in six eyes $(0.96 \%)$. It can be explained by passing a tunnel separator in another plane creating a second tunnel. In four cases the original tunnel was found by passing a thin spatula and in the other two eyes, the procedure was aborted.

Corneal melting occurred as an end stage in one of the cases of infectious keratitis. There were two cases of ring migration where melting has started but when explantation occurred, melting stopped.

Visual axis marking should be done before docking and tunnel creation. Purkinje reflex can appear shifted slightly down, and the centration is done away from the pupil. This can result in severe decentration from the visual axis and might cross the pupil resulting in profound visual affection along with glare and haloes. ${ }^{26}$ In the current study, infectious keratitis was $0.6 \%$ while in other studies it was $1.4 \%$ out of 212 eyes operated and there was no statistically significant difference between mechanism of tunnel creation or the ring type used. ${ }^{27}$ All the four eyes presented with infectious keratitis appeared within the 2 months of surgery with no late presentations as seen by Galvis et al and Hofling-Lima et al which the case presented after months (up to 22 months) of implantation. ${ }^{28,29}$ Sterile keratitis is reported in five eyes and it appeared as deposits aggregated in the 
A

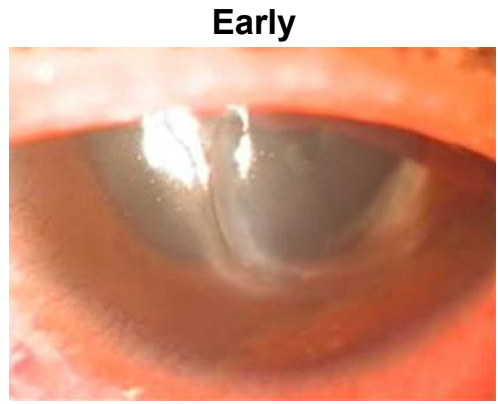

After one week

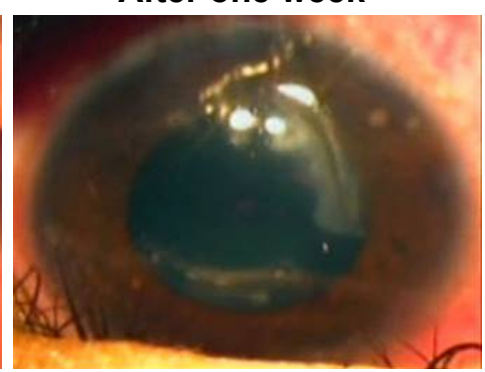

\section{Explantation of extruded ring}
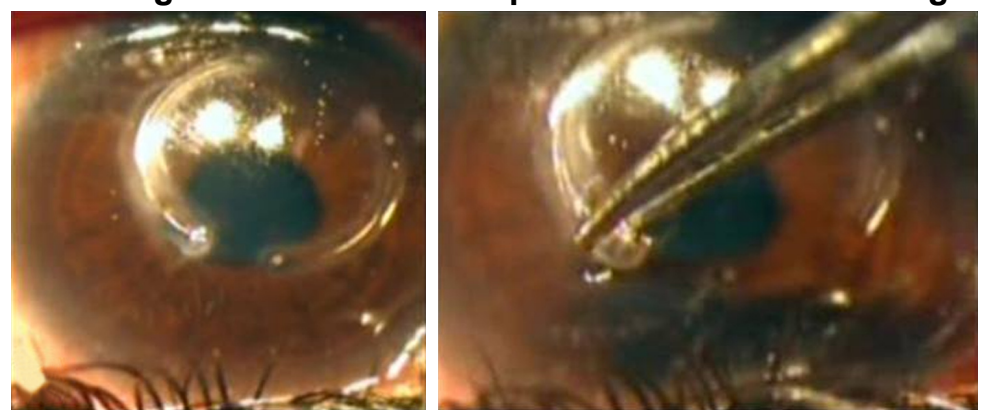

C

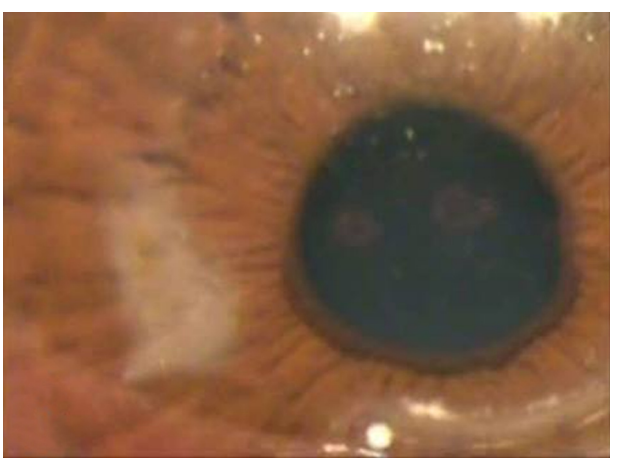

Figure 2 (A) Signs of infection in the presence of Kerarings. (B) Explantation of Keraring. (C) Postexplantation corneal scarring.

space around rings, with no inflammatory manifestations or haze and no effect on the visual acuity. Infection was primarily suspected but after culture of the irrigated saline of the tunnel in two cases and coming back negative, those cases were treated by topical steroids to which they responded well. It was reported as aseptic keratitis by Güell et al ${ }^{30}$ in one case and was treated by ring removal. They linked its presence to rosacea, while two of our cases had spring catarrh. McAlister et $\mathrm{al}^{31}$ reported another case of sterile keratitis and thought that atopic keratoconjunctivitis can be implicated. In both cases reported, ring removal relieved the case, while in our five cases, medical treatment was sufficient and did not affect the final visual outcome. We believe that

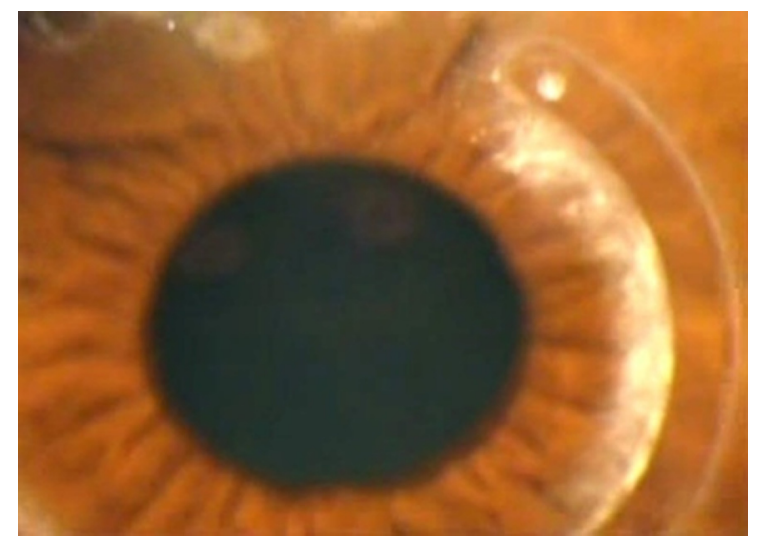

Figure 3 Crystalline deposits around the Keraring. it might be an immune reaction that occurs in the tunnel around the ring in the form of white infiltrates. It might be linked mainly to vernal keratoconjunctivitis cases. Our case series did not encounter corneal incision neovascularization along the follow-up period, while other studies reported its occurrence, ${ }^{32,33}$ which was encountered mostly in cases of mechanical dissection of the corneal tunnel.

Most previous studies investigated the outcomes of INTACS with less studies on Kerarings. Piñero et $\mathrm{al}^{34}$ reported results on difference between INTACS and Keraring on one hand and between mechanical and FS dissection of the cornea on the other hand with no difference between both rings as regards complications. The fact that the ICRS implantation is reversible and with its removal the topographic and refractive values return to its preoperative state $^{13}$ makes dealing with complication less dreadful. Yet, the patient must be counseled that the ICRS do not halt the progression of keratoconus. ${ }^{35}$

\section{Conclusion}

The analysis of our large number of case series (623 eyes) of ICRS (Kerarings) implantation using FS laser allowed encountering diverse number of complications and setting a protocol for dealing with each type, which improved our results over a period of 4 years. Most complications can be abolished if wise decision and meticulous manipulation were put into action. Yet, there are some complications that 
are beyond control because the exact cause is still unclear as sterile keratitis. Experience added value in dealing with unpreventable complications. Over the 4 years of our experience with FS-ICRS, we managed to decrease our rate of complications from $5.5 \%$ in the first year to $0.96 \%$ in the fourth year, making this procedure safe and effective. Passing our experience to refractive surgeons in their early learning curve would hopefully help them evade the preventable complications, thus sparing the patient as well as the surgeon the distress and inconvenience.

\section{Disclosure}

The authors report no conflicts of interest in this work.

\section{References}

1. Bayraktar Bilen N, Hepsen IF, Arce CG. Correlation between visual function and refractive, topographic, pachymetric and aberrometric data in eyes with keratoconus. Int J Ophthalmol. 2016;9(8):1127-1133.

2. Garcia-Lledo M, Feinbaum C, Alio JL. Contact lens fitting in keratoconus. Compr Ophthalmol Update. 2006;7(2):47-52.

3. Wollensak G, Spoerl E, Seiler T. Riboflavin/ultraviolet-a-induced collagen crosslinking for the treatment of keratoconus. Am J Ophthalmol. 2003;135(5):620-627.

4. Coskunseven E, Kymionis GD, Tsiklis NS, et al. One-year results of intrastromal corneal ring segment implantation (KeraRing) using femtosecond laser in patients with keratoconus. Am J Ophthalmol. 2008; 145(5):775-779.

5. Shabayek MH, Alio JL. Intrastromal corneal ring segment implantation by femtosecond laser for keratoconus correction. Ophthalmology. 2007;114(9):1643-1652.

6. Kubaloglu A, Sari ES, Unal M, et al. Long-term results of deep anterior lamellar keratoplasty for the treatment of keratoconus. Am J Ophthalmol. 2011;151(5):760-767.e1.

7. Sutton $\mathrm{G}$, Hodge $\mathrm{C}, \mathrm{McGhee} \mathrm{CN}$. Rapid visual recovery after penetrating keratoplasty for keratoconus. Clin Exp Ophthalmol. 2008;36(8): 725-730.

8. Schanzlin DJ, Asbell PA, Burris TE, Durrie DS. The intrastromal corneal ring segments. Phase II results for the correction of myopia. Ophthalmology. 1997;104(7):1067-1078.

9. Burris TE. Intrastromal corneal ring technology: results and indications. Curr Opin Ophthalmol. 1998;9(4):9-14.

10. Rabinowitz YS. Intacs for keratoconus. Curr Opin Ophthalmol. 2007; 18(4):279-283.

11. Pinero DP, Alio JL. Intracorneal ring segments in ectatic corneal disease - a review. Clin Exp Ophthalmol. 2010;38(2):154-167.

12. Saib N, Bonnel S, Fenolland JR, et al. Intrastromal corneal rings and corneal collagen crosslinking for progressive keratoconus: comparison of two sequences. Eye (Lond). 2015;29(2):294-295.

13. Alio JL, Artola A, Ruiz-Moreno JM, Hassanein A, Galal A, Awadalla MA. Changes in keratoconic corneas after intracorneal ring segment explantation and reimplantation. Ophthalmology. 2004;111(4):747-751.

14. Colin J, Cochener B, Savary G, Malet F, Holmes-Higgin D. INTACS inserts for treating keratoconus: one-year results. Ophthalmology. 2001; 108(8):1409-1414.

15. Alio JL, Artola A, Hassanein A, Haroun H, Galal A. One or 2 Intacs segments for the correction of keratoconus. $J$ Cataract Refract Surg. 2005;31(5):943-953

16. Daxer A. Adjustable intracorneal ring in a lamellar pocket for keratoconus. J Refract Surg. 2010;26(3):217-221.
17. Sugar A. Ultrafast (femtosecond) laser refractive surgery. Curr Opin Ophthalmol. 2002;13(4):246-249.

18. Tunc Z, Helvacioglu F, Sencan S. Evaluation of intrastromal corneal ring segments for treatment of keratoconus with a mechanical implantation technique. Indian J Ophthalmol. 2013;61(5):218-225.

19. Ertan A, Kamburoglu G, Akgun U. Comparison of outcomes of 2 channel sizes for intrastromal ring segment implantation with a femtosecond laser in eyes with keratoconus. J Cataract Refract Surg. 2007; 33(4):648-653.

20. Vega-Estrada A, Alio JL, Brenner LF, Burguera N. Outcomes of intrastromal corneal ring segments for treatment of keratoconus: five-year follow-up analysis. J Cataract Refract Surg. 2013;39(8): $1234-1240$.

21. Coskunseven E, Kymionis GD, Tsiklis NS, et al. Complications of intrastromal corneal ring segment implantation using a femtosecond laser for channel creation: a survey of 850 eyes with keratoconus. Acta Ophthalmol. 2011;89(1):54-57.

22. Ertan A, Kamburoglu G, Bahadir M. Intacs insertion with the femtosecond laser for the management of keratoconus: one-year results. $J$ Cataract Refract Surg. 2006;32(12):2039-2042.

23. Ertan A, Bahadir M. Topography-guided vertical implantation of Intacs using a femtosecond laser for the treatment of keratoconus. $J$ Cataract Refract Surg. 2007;33(1):148-151.

24. Ratkay-Traub I, Ferincz IE, Juhasz T, Kurtz RM, Krueger RR. First clinical results with the femtosecond neodymium-glass laser in refractive surgery. J Refract Surg. 2003;19(2):94-103.

25. Carrasquillo KG, Rand J, Talamo JH. Intacs for keratoconus and postLASIK ectasia: mechanical versus femtosecond laser-assisted channel creation. Cornea. 2007;26(8):956-962.

26. Zare MA, Hashemi H, Salari MR. Intracorneal ring segment implantation for the management of keratoconus: safety and efficacy. J Cataract Refract Surg. 2007;33(11):1886-1891.

27. Mulet ME, Perez-Santonja JJ, Ferrer C, Alio JL. Microbial keratitis after intrastromal corneal ring segment implantation. J Refract Surg. 2010;26(5):364-369.

28. Galvis V, Tello A, Delgado J, Valencia F, Gómez AJ, Diaz LA. Late bacterial keratitis after intracorneal ring segments (Ferrara ring) insertion for keratoconus. Cornea. 2007;26(10):1282-1284.

29. Hofling-Lima AL, Branco BC, Romano AC, et al. Corneal infections after implantation of intracorneal ring segments. Cornea. 2004; 23(6):547-549.

30. Güell JL, Merce M, Salinas C, Elies D, Gris O, Manero F. Four-year follow-up of intrastraomal corneal ring segments in patients with keratoconus. J Emmetropia. 2010;1(1):9-15.

31. McAlister JC, Ardjomand N, Ilari L, Mengher LS, Gartry DS. Keratitis after intracorneal ring segment insertion for keratoconus. $J$ Cataract Refract Surg. 2006;32(4):676-678.

32. Alio JL, Shabayek MH, Artola A. Intracorneal ring segments for keratoconus correction: long-term follow-up. J Cataract Refract Surg. 2006;32(6):978-985.

33. Kanellopoulos AJ, Pe LH, Perry HD, Donnenfeld ED. Modified intracorneal ring segment implantations (INTACS) for the management of moderate to advanced keratoconus: efficacy and complications. Cornea . 2006;25(1):29-33

34. Pinero DP, Alio JL, El Kady B, et al. Refractive and aberrometric outcomes of intracorneal ring segments for keratoconus: mechanical versus femtosecond-assisted procedures. Ophthalmology. 2009;116(9): $1675-1687$.

35. Vega-Estrada A, Alio JL, Plaza-Puche AB. Keratoconus progression after intrastromal corneal ring segment implantation in young patients: five-year follow-up. J Cataract Refract Surg. 2015;41(6):1145-1152. 


\section{Publish your work in this journal}

Clinical Ophthalmology is an international, peer-reviewed journal covering all subspecialties within ophthalmology. Key topics include: Optometry; Visual science; Pharmacology and drug therapy in eye diseases; Basic Sciences; Primary and Secondary eye care; Patient Safety and Quality of Care Improvements. This journal is indexed on

Submit your manuscript here: http://www.dovepress.com/clinical-ophthalmology-journal
PubMed Central and CAS, and is the official journal of The Society of Clinical Ophthalmology (SCO). The manuscript management system is completely online and includes a very quick and fair peer-review system, which is all easy to use. Visit http://www.dovepress.com/ testimonials.php to read real quotes from published authors. 